\title{
SHIFTING THE FOCUS OF DISCUSSION: FROM COST (UNDER)ESTIMATION TO COST REDUCTION
}

\author{
Lauri Koskela $^{1}$ and Glenn Ballard ${ }^{2}$
}

\begin{abstract}
In the last five years, two fierce academic debates have emerged in connection to cost planning in infrastructure projects - a domain which usually is not known as raising passions. The topic debated is alleged - or recommended - underestimation of project costs. Flyvbjerg has promoted the view that cost overruns in transport infrastructure projects are caused by initial cost underestimation, due intentional strategic misrepresentation on the part of project promoters. Love and his co-authors have attacked on Flyvbjerg's views, claiming that such cost overruns are primarily caused by natural, evolutionary scope changes. In turn, Flyvbjerg has objected the earlier suggestion of Hirschman to underestimate project costs, for getting the project started and for unleashing the creativity needed achieve the budget. Both debates have created several rounds of papers.

In this presentation, we contend that in these debates, the focus is partially misplaced, and the conceptualisation of cost planning too narrow. We argue that the primary focus of cost management should be on cost reduction, rather than on cost estimation. We contend that cost formation is a process controlled by man: costs inflate if they are allowed to do so; costs are reduced with will, effort and apt conceptual and methodological knowledge.

For justifying this argument, it is helpful to consider the underlying inferences in cost management. Deduction of total costs from the costs of components is a common inference in cost management. Induction of cost estimates from prior cost data is likewise very common. Reasoning backwards, in terms of regressive or abductive reasoning, is also used. Regressive reasoning answers to the question: How much can we get when using a given sum of money? Abductive reasoning answers to the question: How can we creatively reduce the costs?

The common conceptualization of cost management as cost estimation leads to a situation where deduction and induction are given a privileged or exclusive role as types of reasoning, thus overlooking regressive and abductive reasoning. We recommend applying regressive and abductive reasoning actively as means towards controlling and reducing costs.
\end{abstract}

\section{KEYWORDS}

Cost estimation, cost management, inference types.

1 Professor, School of Art, Design and Architecture, University of Huddersfield, UK, 1.koskela@hud.ac.uk, orcid.org/0000-0003-4449-2281

2 Research Associate, Project Production Systems Laboratory, University of California, Berkeley, CA 94720-1712, USA, gballard@ berkeley.edu, orcid.org/0000-0002-0948-8861 


\section{INTRODUCTION}

Since the seminal paper (Flyvbjerg, Holm and Buhl 2002), Flyvbjerg has contended, in a stream of publications, that in transport infrastructure projects, costs are underestimated due to strategic misrepresentation, in simple terms, lying. Recently, Love and AhiagaDagbui (2018) forcefully attacked the views by Flyvbjerg and his collaborators, comparing them to fake news. This criticism addresses several technical aspects of the empirical study by Flyvbjerg and his colleagues, and, most importantly, the claim that cost underestimation can best be explained by strategic misrepresentation. In turn, Love and Ahiaga-Dagbui (2018) forward an explanation related to evolutionary scope changes for cost underestimation.

In turn, Flyvbjerg (2016) recently critically discussed the idea of a Hiding Hand, originally proposed by Hirschman (1967). The Hiding Hand refers to underestimating a project's cost or difficulties for inducing creative action. For Flyvbjerg, this equates to actively recommending the very root cause for cost overruns, on which he has been trying to shed critical light.

These debates are useful, not only for creating the possibility of clarifying the topics of disagreements, but also as they lay bare strands of theoretical arguments in mainstream cost management. We contend that there are considerable gaps in the arguments by the parties. Namely, although the explanations of the parties refer to phenomena that certainly exist in connection to transportation (and other) projects, more important explanations are missing. Our main argument, inspired by Ohno (2012), is that cost formation should be seen as a process controlled by man - human agency plays a role in cost management, which thus should be classified as a technical science. This implies that cost reduction should be seen as the main task of cost management, rather than cost estimation. For justifying these arguments, we discuss the underlying inferences in cost management: deduction, induction, abduction and regression.

The paper is structured as follows. The next section presents a short summary of the two debates as well as our critical evaluation of them. Subsequently, a theoretical view of cost management, when understood as a technical discipline, and in terms of reasoning, is presented. Based on this wider conceptualization, cost management is discussed and new avenues for it are proposed. A section on conclusions completes the paper.

\section{THE TWO DEBATES}

In the following, the basic arguments on project failure of the parties in the two debates are briefly outlined, along with countermeasures suggested.

\section{THE DEBATE BETWEEN FLYVBJERG AND LOVE}

According to Flyvbjerg et al. (2018), "[t]he root cause of cost overrun is human bias, psychological and political". This bias, called planning fallacy, manifests itself either through delusion, in the form of optimism bias, or through deception, in the form of strategic misrepresentation or lying. As the primary countermeasure to these root causes of cost overruns, Flyvbjerg (2008) offers reference class forecasting (making cost estimates based on the costs of similar recent projects).

In turn, Love pinpoints changing conditions, requirements, and scope as the reasons for cost overruns (Love \& al. 2019). Basically, he proposes better cost estimating as a solution to the cost overrun problem, and mentions BIM as a promising tool in this regard. 


\title{
THE DEBATE ON HiRSCHMAN'S VIEWS
}

Based on his studies on development projects, Hirschman (1967) suggests underestimating a project's cost or difficulties (or overestimating benefits) for inducing creative action. For him, underestimating is the solution in view of the uncontrollability of the necessary creativity in the realization of the project, and a means for getting projects started. He explains the rationale behind the concept of Hiding Hand as follows (Hirschman 1967):

\begin{abstract}
We may be dealing here with a general principle of action. Creativity always comes as a surprise to us; therefore we can never count on it and we dare not believe in it until it has happened. In other words, we would not consciously engage upon tasks whose success clearly requires that creativity be forthcoming. Hence, the only way in which we can bring our creative resources fully into play is by misjudging the nature of the task, by presenting it to ourselves as more routine, simple, undemanding of genuine creativity than it will turn out to be. Or, put differently: since we necessarily underestimate our creativity it is desirable that we underestimate to a roughly similar extent the difficulties of the tasks we face, so as to be tricked by these two offsetting underestimates into undertaking tasks which we can, but otherwise would not dare, tackle.
\end{abstract}

These suggestions by Hirschman are of course diametrically opposed to the views of Flyvbjerg. Based on an empirical, quantitative analysis, Flyvbjerg (2016) claims that Hirschman's Hiding Hand can be identified only in a fifth of projects, the rest rather having cost overruns and benefit shortfalls, and strongly rejects the notion of the Hiding Hand (see also (Flyvbjerg \& Sunstein 2016, Flyvbjerg 2018b). In turn, Flyvbjerg's claims have triggered several papers defending Hirschman (e.g. Ika 2018, Lepenies 2018, Kreiner 2020).

\section{Critical Evaluation}

We contend that in the discussion between Love and Flyvbjerg, there is a fundamental misconception around cost management. Namely, there is the failure to acknowledge the role of human agency in cost management. One important aspect of human agency is revealed in the saying by Ohno (2012): "Costs do not exist to be calculated. Costs exist to be reduced." Just calculating or predicting costs implies a natural science approach to the phenomena causing costs: they are out there and we as external observers examine them. This is the attitude of a quantity surveyor or an economist to cost. The former profession emerged to safeguard clients from unscrupulous builders, and quantity surveyors' viewpoint has been external to the construction process from the outset. The economist looks at production as a black box, and by force is outside that.

The other attitude, subscribed by Ohno, is the engineering (or technical) attitude: costs are both starting points and outcomes from our designing and planning and controlling. We can influence them. Note that this attitude embraces the natural science approach to costs: we still need to predict costs.

What would then a technical approach to cost management be in the case of projects? An infrastructure project consists of design and construction stages; project costs show partially different characteristics in these two stages. In the design stage, costs depend on the efforts of designers to take the budgeted costs to be a starting point of design and to go creatively (through abduction) beyond the solutions that are well-known. Both 
Flyvbjerg and Love seem to fail to account for such deliberate efforts towards cost reduction. In the construction stage, there are avoidable and unavoidable costs; the amount of avoidable costs (cost for waste ${ }^{3}$ ) is dependent on appropriate leadership as well as managerial effort and effective managerial methods. Again, both Flyvbjerg and Love largely fail to account for avoidable costs.

Regarding then Hirschman, he accepts the role of human agency (and thus the technical attitude), especially in the sense of creativity, but views that it is incontrollable and is only triggered when the situation needs that. We consider this to be a too narrow and constraining view on creativity.

For justifying and expanding our arguments for the sake of cost management as a technical discipline, it is helpful to consider the major ways of controlling and reducing costs, as well their underlying inferences.

\section{COST MANAGEMENT AS COST REDUCTION: THE METHODS TO CONTROL AND REDUCE COSTS}

What then does this technical approach to costs embrace (besides cost prediction that of course remains to be a necessary step)? There are at least four methods to control and reduce costs:

- Steering design and construction towards allowed costs.

- Encouraging, in design and construction, more intense search of the best solutions.

- Encouraging creativity for finding novel, less costly options.

- Applying waste reduction for diminished costs.

These four methods are explained in the following.

\section{STEERING}

The question is about taking the cost target to be a requirement in design, rather than an outcome. Surely, in almost all design, there is an element of steering towards acceptable costs, but traditionally the decision cycle has been too long to be effective, leading to (too) late attempts of cost reduction.

\section{MORE INTENSE SEARCH}

A second viewpoint is based on considerations related to economics. The axiomatic assumption in economics is that economic actors are optimizing in their decisions. However, as advanced by Simon (1990), this is an unrealistic assumption, for several reasons, especially because of bounded rationality and search costs for finding the optimum; in practice people "satisfice", select a satisfactory option. Thus, a gap (usually) remains between the selected option and the optimal option (should it be possible to determine it). It may be possible to narrow down this gap, and thus the question is about avoidable costs.

Accuracy of cost estimates is not the main topic of this paper. However, it is appropriate to state in passing that cost predictions are inaccurate also because there is a failure to predict the amount of waste costs, especially when the mainstream approach denies their existence (except in gregarious cases) and has no or little understanding on what is causing waste and how to reduce waste. The occurrence of waste is often emergent and varies from project to project. Flyvbjerg and Love fail to orderly conceptualize the phenomenon of waste. 


\section{Encouraging Creativity}

A third viewpoint is related to creativity. Through creativity, novel (in the situation) solutions, possibly providing cost advantages, can be achieved.

\section{REDUCING WASTE}

The occurrence of waste is ubiquitous and significant in construction. In this situation, related avoidable costs provide a major source of cost reduction opportunities.

\section{DISCUSSION}

The fundamental misconception of cost management as a natural science discipline leads to a situation where prediction of costs is given the dominant or exclusive role, and the ways of controlling and reducing costs are sidelined. In practice, predicting, controlling and reducing costs are realized through different types of inferences, and for the sake of a complete analysis, it is necessary to discuss them.

\section{INFERENCES USED IN COST MANAGEMENT}

For identifying the dominant inferences used in cost management, it is appropriate to start from the typical information needs occurring in relation to costs. These can be expressed through questions. We contend that for a client there are three questions of immediate interest in relation to cost:

1. Given a scope or design, how much will it cost?

2. Given a cost (or price), what will I get?

3. Given a difference between the estimated cost and the cost that can be afforded, how can the project be realized?

Note that there is an additional, fourth question in the background:

1. Given recent realized costs, which cost data should I use for my project?

In the field of pedagogy, it is common to distinguish inferential questions from other question types (Zucker et al. 2010). The criterion of an inferential question is that an inference is needed for responding to it. All the mentioned four questions are inferential, and remarkably, a particular inference type is respectively employed:

1. This is a deductive inference, proceeding forward, from number of things and activities and their unit costs (or prices) to total costs.

2. Regressive inferences are opposite to deductive inferences, they proceed backwards. A client may assess that a business case allows a certain amount of money to be used for a construction project. How many square meters and at which quality level can then be afforded?

3. In turn, abductive inferences are creative. Their starting point is a problem seemingly without a solution. However, a creative abduction provides an insight that solves the problem. This kind of situation emerges, say, if the cost of an existing product needs to be reduced by $20 \%$ due to competitive pressures.

4. Inductive inferences are used for determining the unit costs in cost management. These inferences are based on observation of costs in the relevant marketplaces.

In the following, these inference types, as they occur in cost management, are examined in more detail. 


\section{DEDUCTIVE INFERENCES}

Deduction can be defined as follows (Baker 2017): "A deduction is any sequence of statements each of which is derived from some initial set of statements (the premises) or from a prior statement in the sequence." Deduction equals thus reasoning forward.

A deductive inference in construction cost management is typically of the form: The building will incorporate $\mathrm{x}$ tonnes of steel, with a price y per tonne, thus the total cost of steel will be xy. A deductive inference is thus used for prediction of the cost.

What is thus critical is (1) that all causes of costs (materials, activities, overheads) have been correctly identified and determined (in product and work breakdown structure) regarding their numerical value, and (2) that the unit cost is correct (with no systematic bias). Unfortunately, there are potential problems regarding both critical issues.

Regarding "all causes of costs", there are several reasons why some causes are not identified or known in early stages of a project. The tendency of scope creep has been discussed in the literature (Kuprenas \& Nasr 2003). During the project, new activities may emerge as necessary, or activities turn out to be more difficult that assumed. However, perhaps a dominating question may be that a part of cost is caused by nonnecessary activities (or materials, etc.), leading thus to avoidable cost. The prediction of the widely varying occurrence of waste is in practice impossible.

The correctness of the unit cost is discussed below.

\section{REGRESSIVE INFERENCES}

Regressive inferences are similar to deductive inferences in being based on causality, but proceed in opposite direction, backward from outcomes to causes, while deduction proceeds forward, from causes to outcomes. Besides direction, there is another essential difference: the deductive inference is objective, each cause by necessity produces its predetermined outcome. Instead, as several causes may produce the same outcome, a regressive inference is often selective, that is, there is a subjective selection among different known causes.

Regressive inferences are the main ingredient of design (Pikas 2019), and through them, the means-ends chain from requirements to the smallest element designed is created. From the viewpoint of cost management, regressive inferences are thus related to steering towards cost targets, and to extending the range of options for the sake of improved decisions (that is, pushing to the optimum in terms what is generally known, rather than creating new alternatives) - Empirical research shows that experienced designers tend to gravitate towards solution conjectures related to their prior experience (Cross 2004).

Regressive inferences, being counterparts to deductive inferences in opposite direction, have the same critical issues as the latter.

A further function for regressive inferences is in finding the root cause for waste.

\section{ABDUCTIVE INFERENCES}

Abduction was defined by the American philosopher and scientist Peirce (1934) as the only type of inference that produces new ideas. Although abduction has mostly been addressed in the context of scientific inventions, it has also been recognised as a key inference in design (Koskela, Paavola \& Kroll 2018). In the design (or planning) context, an abductive inference leads to a solution that goes beyond being habitual or being selected, purportedly as the best, among existing, generally known options. Rather, an abductive solution shows novelty in the context. In the context of cost management, an 
abductive inference does not seek to predict or estimate a cost of a thing or process, but rather to find a thing or process with such novelty that it can be realized with reduced cost.

\section{INDUCTIVE INFERENCES}

A classical definition of induction is as follows by Hume (Ambrose 1947): "instances of which we have had no experience resemble those of which we have had experience". A typical inductive inference in cost management is as follows: Something has cost in the past, in same circumstances, $\mathrm{x}$, let us assume that this will be the case in the future. - Also predicted inflation may be an induction.

Inductions on cost may be on different levels, from elemental level (cost of a type of material or work) to the project level. At the elemental level, there are commercial databases on average cost of different types of material and work, based on induction. At the project level, the question is about reference class cost prediction (Flyvbjerg 2008).

However, there is a major problem in relation to cost induction. Namely, any observed cost (per unit) may have a share of avoidable cost but its amount is usually not visible. For example, Koskenvesa \& al. (2010) report that the Finnish productivity data for different types of construction work, as presented in a national, continuously updated database, contain a considerable share of waste time, which then migrates, as accepted waste, into schedules, task durations, contracts and cost estimations.

\section{RELATION OF INFERENCE TYPES TO THE DIFFERENT METHODS OF TEChNiCAL APPROACH to CoST MANAGEMENT}

Now, we are in the position of presenting an overview on the inference types used by each method of the technical approach to cost management (Table 1): regressive and abductive inferences are in the central position, while deductive and inductive inferences are used as supporting types of reasoning (except in cost prediction).

Table 1. Methods and their inference types in the technical approach to cost management.

\begin{tabular}{ccc}
\hline $\begin{array}{c}\text { Method in the technical approach } \\
\text { to cost management }\end{array}$ & Primary inference types & Secondary inference types \\
\hline Cost prediction & $\begin{array}{c}\text { Deductive and inductive } \\
\text { inferences }\end{array}$ & - \\
Steering & $\begin{array}{c}\text { Regressive inferences } \\
\text { Regressive and deductive } \\
\text { inferences } \\
\text { Better decision-making }\end{array}$ & Deductive and inductive inferences \\
Abductive inferences & Inductive inferences \\
Creativity & $\begin{array}{c}\text { Degressive inferences (for finding } \\
\text { the root causes for waste) }\end{array}$ & Deductive and inductive inferences \\
\hline
\end{tabular}

\section{HOW TO GET THE TECHNICAL APPROACH TO COST MANAGEMENT REALIZED?}

Up to recent times, the fragmented and siloed organizing of construction projects made it difficult to use the technical approach to cost management. Along with influences from other sectors, organizational innovations and maturation of digitised construction, new related practices and methods have emerged, such as Target Value Design (TVD), Setbased Design, Choosing by Advantages, etc., which can be used as part of cost management in the technical sense. In view of space limitations, only the two central inferences in the technical approach to cost management are commented in the following. 


\section{REGRESSIVE INFERENCES}

Regression in steering to targets may seem straightforward, but actually already conceptual estimating/target setting prior to design requires a careful and systematic approach. One possibility is to identify different functions to be performed in the building, and to use prior statistical data (cost per function) for setting the target cost. A simple variant of this is the unit method (Kirkham 2014), where one functional unit is used for costing (say beds in a hospital ward). Another option is provided by the method described in (Pennanen, Ballard \& Haahtela 2011), which is based on a software structured to transform the voice of the customer into a constructable Building Information Model. This BIM constructs all the quantities and costs of the building components before the design starts, basing on the client's needs. However, it has no visual read-out because the intention is to allow designers to be constrained only by functionalities, capacities and target cost, and to otherwise have free rein to deliver architectural and other soft qualities.

Furthermore, regression can reveal the need for abduction when conflicts between design criteria must be resolved, because otherwise the project purpose is unachieveable. A weaker sense of "must be resolved" also exists when project objectives that are not essential to its fundamental purpose can only delivered through invention (Ballard, et al., 2020).

All in all, our knowledge on the current state and developments opportunities of regression is still scant.

\section{ABDUCTIVE INFERENCES}

Abduction may be the most powerful type of inference. However, the challenge is that it cannot be conducted in a deliberate manner - there is hardly a recipe for abduction. Nevertheless, researchers have come up with factors which are encouraging or discouraging creativity - and thus abduction (the two first columns in Table 2).

Table 2. Factors influencing creativity and corresponding features in TVD

\begin{tabular}{|c|c|c|}
\hline $\begin{array}{l}\text { Factor influencing } \\
\text { creativity }\end{array}$ & Explanation of the factor & $\begin{array}{c}\text { Corresponding feature in the TVD } \\
\text { practice }\end{array}$ \\
\hline Progress principle & $\begin{array}{l}\text { Making progress in meaningful work leads to } \\
\text { intrinsic motivation and further to creativity } \\
\text { (Amabile \& Pratt 2016). }\end{array}$ & $\begin{array}{l}\text { The progress towards the target cost is } \\
\text { prominently visible. }\end{array}$ \\
\hline $\begin{array}{l}\text { Intrinsic and extrinsic } \\
\text { motivators }\end{array}$ & $\begin{array}{l}\text { Intrinsic motivation is conducive to creativity; } \\
\text { controlling extrinsic motivation is detrimental to } \\
\text { creativity but informational and enabling } \\
\text { extrinsic motivation can be conducive (Amabile } \\
\text { \& Pratt 2016). }\end{array}$ & $\begin{array}{l}\text { Intrinsic motivation is provided through } \\
\text { progress, and such extrinsic motivators } \\
\text { as the gain/pain sharing mechanism } \\
\text { and the clear targets may act in a } \\
\text { synergistic manner. }\end{array}$ \\
\hline Work environment & $\begin{array}{l}\text { Clear organizational goals, value placed on } \\
\text { innovation, sufficient time, clear project goals } \\
\text { and autonomy in how to meet project goals, etc. } \\
\text { are related to creativity (Amabile \& Pratt 2016). }\end{array}$ & $\begin{array}{l}\text { Many of the stated work environment } \\
\text { factors may exist in an TVD } \\
\text { environment. Especially, cost } \\
\text { reductions are expected to occur over } \\
\text { the project duration, and thus there is } \\
\text { sufficient time. }\end{array}$ \\
\hline $\begin{array}{l}\text { Collaboration and } \\
\text { discussion }\end{array}$ & $\begin{array}{c}\text { Participative decision-making, collaboration } \\
\text { (Amabile \& Pratt 2016) and discussion (Koskela } \\
\text { \& Kroll 2019) stimulate creativity. }\end{array}$ & $\begin{array}{l}\text { Both wide collaboration and one-to-one } \\
\text { discussions are encouraged. }\end{array}$ \\
\hline Affect & $\begin{array}{l}\text { Positive relation between affect and creativity: } \\
\text { positive mood leads to higher levels of creativity } \\
\text { (Amabile \& Pratt 2016). }\end{array}$ & $\begin{array}{c}\text { Applied methods, like Last Planner, } \\
\text { lead to positive mood (Arroyo \& Lang } \\
\text { 2018). }\end{array}$ \\
\hline
\end{tabular}

Further, in Table 2 it is examined how abductive inferences are being supported in the practices related to TVD. Even if creativity aspects as such have not been a starting point 
in the development of the TVD approach, an initial analysis shows the approach is surprisingly compatible with the suggestions of creativity research.

There are two creativity factors which are especially interesting from the viewpoint cost management, namely the influence of available time and collaboration. Amabile, Hadley and Kramer (2002) contend, based on extensive empirical studies, that time pressure discourages creativity (however less if the employees feel a sense of mission). Instead, one-to-one collaborations support creativity according to these authors. The role of verbalization, discussion and debate was found also by Koskela and Kroll (2020) as important underlying factors for abduction.

However, our knowledge on the current state and development opportunities of abduction in construction cost management, as well as more generally in construction management, is very modest, and thus there are fertile topics for research on offer.

\section{CONCLUSIONS}

The common natural science conceptualization of cost management, subscribed by Flyvbjerg and Love, leads to a situation where deduction and induction are given a privileged or exclusive role as types of reasoning in dealing with costs, thus overlooking regressive and abductive reasoning. In Hirschman's project management concept, creativity through abductive reasoning is acknowledged, but it is considered uncontrollable and not actively managed. We recommend applying regressive and abductive reasoning actively and systematically as means towards controlling and reducing costs. Also, we suggest that the mentioned forms of reasoning in construction cost management invite for fertile opportunities for descriptive and prescriptive research.

\section{REFERENCES}

Amabile, T. M., Hadley, C. N., \& Kramer, S. J. (2002). "Creativity under the gun." Harvard Business Review, 80, 52-63.

Amabile, T.M., \& Pratt, M.G. (2016). "The dynamic componential model of creativity and innovation in organizations: Making progress, making meaning." Research in organizational behavior, 36, 157-183.

Ambrose, A. (1947). "The problem of justifying inductive inference." The Journal of Philosophy, 44(10), 253-272.

Arroyo, P., and Long, D. (2018). "Collaborative Design Decisions" In: Proc. 26th Annual Conference of the International. Group for Lean Construction (IGLC), González, V.A. (ed.), Chennai, India, pp. 463-472. doi.org/10.24928/2018/0509.

Baker, A. (2017) "Non-Deductive Methods in Mathematics", The Stanford Encyclopedia of Philosophy (Winter 2017 Edition), Edward N. Zalta (ed.), URL https://plato.stanford.edu/archives/win2017/entries/mathematics-nondeductive/.

Ballard, G., Arroyo, P. and Chiu, S. (2020). "Conflicting Design Requirements". 2020 Lean in Design Forum Lean Construction Institute. Available at p2sl.berkeley.edu.

Cross, N. (2004). "Expertise in design: an overview." Design studies, 25(5), 427-441.

Flyvbjerg, B. (2008). "Curbing optimism bias and strategic misrepresentation in planning: Reference class forecasting in practice.” European Planning Studies, 16(1), 3-21.

Flyvbjerg, B. (2016). "The fallacy of beneficial ignorance: A test of Hirschman's hiding hand." World Development, 84, 176-189.

Flyvbjerg, B. (2018a). Critics don't understand behavioral science. Local Trans. Today, April 27, pp. 3-4, https://www.transportxtra.com/publications/local-transporttoday/news/56703/in-depth-academics-clash-on-causes-of-transport-cost-overruns. 
Flyvbjerg, B. (2018b). "Planning fallacy or hiding hand: Which is the better explanation?" World Development, 103, 383-386.

Flyvbjerg, B. and Sunstein, C.R. (2016). "The principle of the malevolent hiding hand; or, the planning fallacy writ large." Social Research: An International Quarterly, 83(4), 979-1004.

Flyvbjerg, B., Ansar, A., Budzier, A., Buhl, S., Cantarelli, C., Garbuio, M., ... \& van Wee, B. (2018). Five things you should know about cost overrun. Transportation Research Part A: Policy and Practice, 118, 174-190.

Flyvbjerg, B., Holm, M. S., \& Buhl, S. (2002). "Underestimating costs in public works projects: Error or lie?" Journal of the American Planning Association, 68(3), 279-295.

Hirschman, A.O. (1967). "The principle of the hiding hand." The Public Interest, 6, 1023.

Ika, L. A. (2018). "Beneficial or detrimental ignorance: The straw man fallacy of Flyvbjerg's test of Hirschman's hiding hand." World Development, 103, 369-382.

Kirkham, R. (2014). Ferry and Brandon's cost planning of buildings. John Wiley \& Sons.

Koskela, L., Paavola, S., \& Kroll, E. (2018). "The role of abduction in production of new ideas in design." In Advancements in the Philosophy of Design (pp. 153-183). Springer, Cham.

Koskenvesa, A., Koskela, L., Tolonen, T. and Sahlsted, S. (2010). "Waste and labor productivity in production planning: case Finnish construction industry", in: 18th Annual Conference of the International Group for Lean Construction, Haifa, Israel.

Kreiner, K. (2020). "Conflicting notions of a project: The battle between Albert O. Hirschman and Bent Flyvbjerg." Project Management Journal, 51(4) 400-410.

Kuprenas, J. A., \& Nasr, E. B. (2003). "Controlling design-phase scope creep." AACE International Transactions, CS11-CS15.

Lepenies, P. H. (2018). "Statistical tests as a hindrance to understanding: What the controversy around the "Hiding Hand" reveals about research in the social sciences and conceals about project management." World Development, 103, 360-365.

Love, P.E.D. and Ahiaga-Dagbui. D.D. (2018). "De-bunking 'fake news' in a post-truth era: the plausible untruths of cost underestimation in transport infrastructure projects." Transport. Res. A: Policy and Practice, 113, pp. 357-368.

Love, P.E.D., Sing, M. C. P., Ika, L.A., \& Newton, S. (2019). "The cost performance of transportation projects: The fallacy of the planning fallacy account." Transportation Research Part A: Policy and Practice, 122, 1-20.

Ohno, T. (2012). Taiichi Ohno's Workplace Management: Special 100th Birthday Edition, McGraw Hill Professional.

Peirce, C. S. (1934). "Abduction and Perceptual Judgments." Collected Papers of Charles Sanders Peirce, V (MA: Harvard University Press, 1935), 113-120.

Pennanen, A., Ballard, G., \& Haahtela, Y. (2011). "Target costing and designing to targets in construction." Journal of Financial Management of Property and Construction, 16 (1)52-63.

Pikas, E. (2019). Causality and interpretation: integrating the technical and social aspects of design. Doctoral dissertation. Aalto University.

Simon H.A. (1990). “Bounded Rationality.” In: Eatwell J., Milgate M., Newman P. (eds.) Utility and Probability. The New Palgrave. Palgrave Macmillan, London.

Zucker, T. A., Justice, L. M., Piasta, S. B., \& Kaderavek, J. N. (2010). "Preschool teachers' literal and inferential questions and children's responses during whole-class shared reading." Early Childhood Research Quarterly, 25(1), 65-83. 